\title{
PERAN CEMARA LAUT (Casuarina equisetifolia) DALAM PERBAIKAN IKLIM MIKRO LAHAN PANTAI BERPASIR DI KEBUMEN
}

(The role of Casuarina equisetifolia on micro climate improvement of sandy beach land at Kebumen)

Beny Harjadi

Balai Penelitian dan Pengembangan Teknologi Pengelolaan Daerah Aliran Sungai Jl. A. Yani Pabelan Kartasura PO BOX 295 Surakarta 57102

Email:adbsolo@yahoo.com

Diterima: 8 Februari 2017; Selesai Direvisi: 5 Oktober 2017; Disetujui: 5 Oktober 2017

\begin{abstract}
Sandy beach is a marginal land, when it is not managed properly the conditions will be worsened and at the end it cannot be planted. This marginal land is aggravated by unfavorable conditions such as extreme high temperatures, the presence of salt vapor that causes the plants to die, and the lacking of water for plants. With regard to this matter, it is necessary to conduct a research that aims to determine the role of Casuarina equisetifolia in improving the microclimate of sandy beaches. The research was conducted on sandy beaches in Karanggadung, Petanahan Subdistrict, Kebumen since 2005, with climate observations from 2009 to 2014. The climate observation method is by measuring light, air temperature, humidity, air pressure and altitude. Each measurement used three repetitions for each location and measured twice a day: 07.00 and 16.00. The results showed that the existence of $C$. equisetifolia gave a positive effect on micro climate improvement at Karanggadung Beach, Kebumen which included: 1) decreasing light intencity from 1925 lux to 213 lux, 2) decreasing air temperature from $31{ }^{\circ} \mathrm{C}$ to $\left.25{ }^{\circ} \mathrm{C}, 3\right)$ increasing air humidity from $84 \%$ to $100 \%, 4)$ increasing air pressure from $1007 \mathrm{mb}$ to $1008 \mathrm{mb}$, and 5) increasing sand dune level from $27 \mathrm{~m}$ ASL (Above Sea Level) to $35 \mathrm{~m}$ ASL.
\end{abstract}

Key words: Casuarina equisetifolia; micro climate; wind break; wind erosion; sand dune

\begin{abstract}
ABSTRAK
Pantai berpasir merupakan lahan marginal, jika tidak dikelola dengan baik kondisinya semakin hari akan semakin rusak dan tidak bisa ditanami. Kondisi yang tidak menguntungkan juga ditunjang kondisi iklim yang buruk yaitu suhu yang ekstrim panas, adanya uap garam-garaman yang menyebabkan tanaman mati, dan ketersediaan air bagi tanaman yang sangat kurang. Berkenaan dengan hal tersebut maka perlu dilakukan penelitian yang bertujuan untuk mengetahui peranan Cemara Laut (Casuarina equisetifolia) dalam memperbaiki iklim mikro pantai berpasir. Penelitian dilakukan di pantai berpasir Karanggadung, Kecamatan Petanahan, Kabupaten Kebumen dengan pengamatan iklim dari tahun 2009 sampai 2014. Metode pengamatan iklim dengan mengukur pencahayaan, suhu udara, kelembaban udara, tekanan udara dan ketinggian tempat. Masing-masing dilakukan pengulangan tiga kali pada setiap lokasi dengan pengamatan pagi (07.00) dan sore hari
\end{abstract}


(16.00). Hasil penelitian menunjukkan adanya dampak positif keberadaan Cemara Laut di Pantai Karanggadung, Kebumen terhadap perbaikan iklim mikro meliputi: 1) penurunan intensitas cahaya dari 1925 lux menjadi 213 lux, 2) suhu udara turun dari $31{ }^{\circ} \mathrm{C}$ menjadi 25 ${ }^{\circ} \mathrm{C}$, 3) kelembaban meningkat dari $84 \%$ menjadi $100 \%$, 4) tekanan udara meningkat dari $1007 \mathrm{mb}$ menjadi $1008 \mathrm{mb}, 5$ ) ketinggian tempat mengalami peningkatan $27 \mathrm{~m}$ dpl (dari permukaan laut) menjadi $35 \mathrm{~m}$ dpl.

Kata kunci: Cemara Laut; iklim mikro; tanggul angin; erosi angin; gisik

\section{PENDAHULUAN}

Wilayah pantai berpasir memliki masalah utama antara lain terjadi erosi angin yang berlangsung terus menerus, sehingga kondisi lahan marginal dan sering ditelantarkan. Peristiwa rutin yang terjadi setiap hari tersebut menjadikan lahan pantai berpasir dari hari ke hari semakin memburuk, baik untuk wilayah itu sendiri maupun wilayah yang ada di belakangnya dan lahan di sekitar pesisir pantai.

Dampak buruk peristiwa erosi angin di daerah pantai mengakibatkan (Hani \& Rachman, 2016): 1) tanah lahan pantai berpasir bertekstur kasar dan bersifat lepas sehingga sangat peka atau sensitif terhadap erosi angin, 2) hasil erosi berupa endapan pasir (sand dune) akan menutupi tanaman budidaya di sekitar gisik (gundukan pasir) dan pemukiman yang berada di belakangnya, dan 3) butiran pasir yang mengandung garam terbawa dalam proses erosi angin akan dapat merusak dan menurunkan produktivitas tanaman. Kondisi yang kurang menguntungkan ini menyebabkan tanaman semusim di sekitarnya sulit untuk tumbuh.

Dalam upaya pengurangan dampak buruk dari kecepatan angin di wilayah pantai berpasir perlu dilakukan dengan penanaman tanggul angin. Salah satu tanaman tanggul angin adalah Cemara Laut (Casuarina equisetifolia). Tanaman ini sudah diuji coba di Taiwan yang digunakan untuk mengurangi dan membelokkan kecepatan angin (Budiyanto, 2011). Menurut Daryono et al. (2016) penanaman tanaman tanggul angin atau barrier juga diperlukan dalam budidaya tanaman melon di wilayah pantai berpasir. Penelitian ini bertujuan untuk mengetahui peranan Cemara Laut dalam memperbaiki iklim mikro pantai berpasir.

\section{II.BAHAN DAN METODE}

\section{A. Waktu dan Lokasi}

Penelitian dilakukan selama 6 tahun dari tahun 2009 sampai 2014 di Pantai Karanggadung Kecamatan Petanahan, Kabupaten Kebumen. Secara geografis terletak pada koordinat $109^{\circ} 35^{\prime} 20^{\prime \prime}$ BT sampai $109^{\circ} 36^{\prime} 00^{\prime \prime}$ BT, dan $07^{\circ} 44^{\prime} 45^{\prime \prime}$ LS sampai $07^{\circ} 45^{\prime} 15^{\prime \prime}$ LS. Kondisi geologi tanah berupa endapan alluvium pasiran dan jenis tanah regosol dengan topografi umumnya berombak.

Selama pengamatan total curah hujan tahunan terendah 1605 mm (tahun 2009) dan jumlah hari hujan terpendek 146 hari (tahun 2009) dan tertinggi 1489 dengan jumlah hari hujan terlama 268 hari (tahun 2013), seperti yang terlihat dalam Gambar 
1. Fluktuasi curah hujan tertinggi pada bulan November sampai Januari dan musim kering terjadi pada bulan Juli sampai September. Data tahun 2010 tidak disajikan karena merupakan pencilan yang diduga terjadi kesalahan dan diragukan keakuratannya.

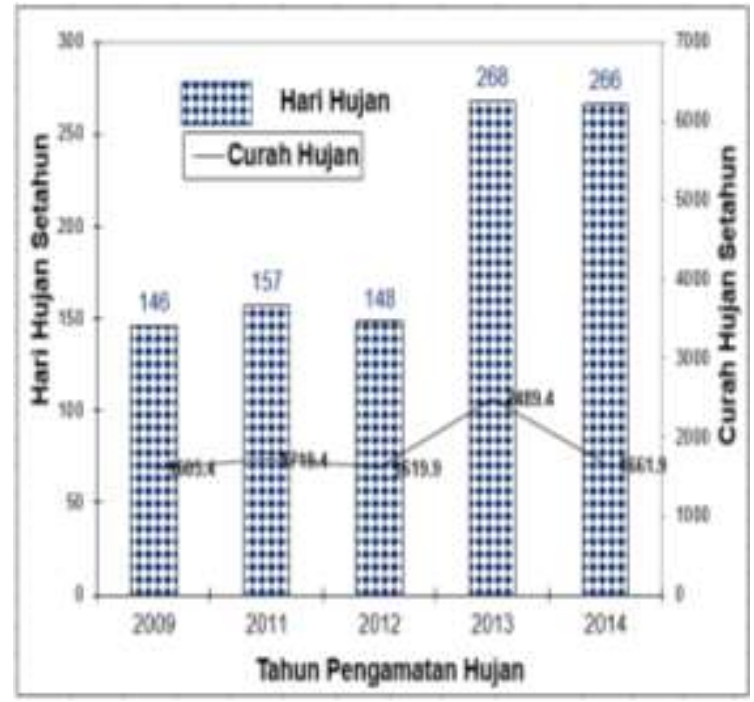

Gambar (Figure) 1. Data curah hujan tahun 2009 sampai 2014 di Kebumen (Rainfall data from 2009 to 2014 in Kebumen)

Sumber(Source): Analisis data primer (Primary data analysis)

\section{B.Bahan dan Alat}

Bahan yang digunakan dalam penelitian antara lain tanaman Cemara Laut pada tepi pantai sejauh $50 \mathrm{~m}$ dari garis pantai saat pasang tertinggi. Alat yang digunakan untuk pengamatan iklim adalah: 1) luxmeter untuk pencahayaan matahari, 2) termometer untuk perubahan suhu udara, 3) higrometer untuk kelembaban udara, 4) barometer untuk tekanan udara, 5) altimeter untuk ketinggian tempat.

\section{C.Metode Penelitian}

Pengamatan kondisi iklim sejak tahun 2009 sampai 2014 dilakukan setiap hari yaitu pada pagi (07.00) dan sore hari (16.00). Khusus pada bulan Oktober 2014 dilakukan pengukuran beberapa parameter: 1) pencahayaan, 2) perubahan suhu, 3) kelembaban, 4) tekanan udara, dan 5) ketinggian tempat. Deskripsi lokasi pengamatan dilakukan pada 6 areal dengan deskripsi lokasi sebagai berikut:

1.Pantai $(\mathrm{P})$ : kondisi tanah pasir terbuka (bera)

2. Dekat pantai (DP): depan Cemara Laut dengan serasah dan rumput berduri

3. Areal Cemara Laut (C): tegakan tahun tanam 2006 (10 tahun)

4. Belakang cemara (BC): tanaman muda bervariasi dari kelapa umur 5 tahun, cemara umur 3 tahun, dan rumput liar.

5.Gisik pasir $(G)$ : gundukan pasir dengan tanaman cemara dari perbanyakan cangkok umur 10 tahun

6. Areal pohon kelapa (K): umur 15 tahun yang bercampur dengan sayur-sayuran dan tanaman hortikultura lainnya.

Pada areal tersebut masing-masing dilakukan tiga kali pengulangan seperti yang terlihat pada Gambar 2 dibawah ini.

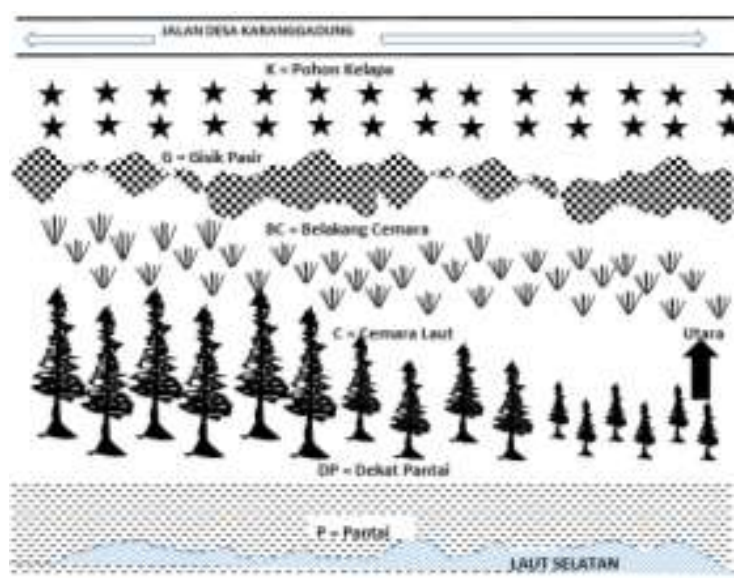

Gambar (Figure) 1. Bentang lahan pantai berpasir Kebumen (The Landscape of south beach Kebumen)

Sumber (Source): $\quad$ Sketsa data primer (Sketches of primary data) 
Keadaan riil kondisi di lapangan dapat dilihat pada foto-foto penutupan lahan (Gambar 3) dari lahan pantai berpasir (P), dekat pantai (DP), Cemara Laut (C), belakang cemara (BC), gisik/ gundukan pasir (G), dan kebun kelapa (K).

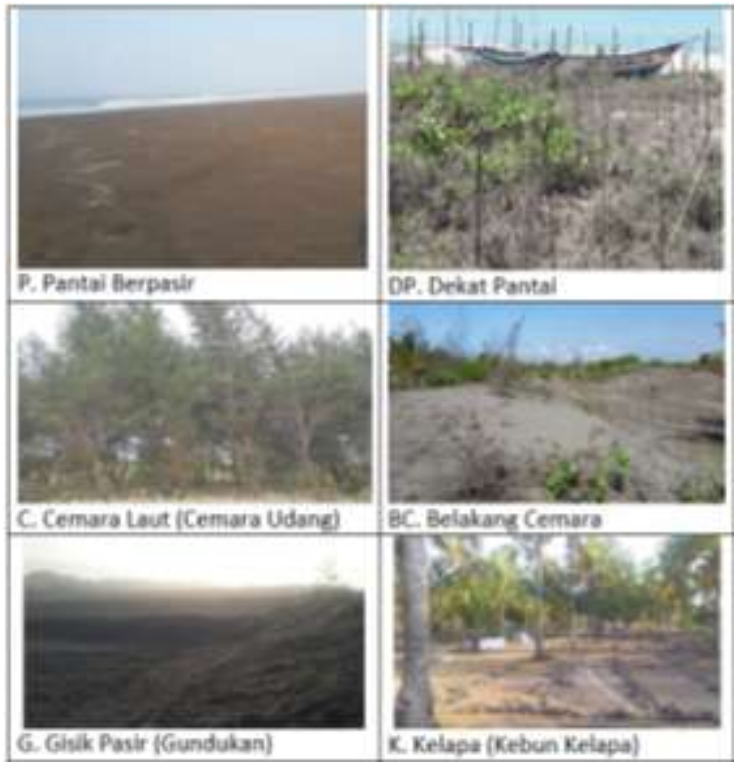

Gambar (Figure) 2. Foto kondisi lahan pantai berpasir Kebumen (Conditions of sandy beach at Kebumen)

Sumber (Source): Koleksi pribadi, 2014

\section{HASIL DAN PEMBAHASAN}

\section{A. Pencahayaan}

Pencahayaan sinar matahari yang masuk ke lahan pantai berpasir sangat fluktuatif. Semakin terbuka lahan maka pencahayaan sangat tinggi dan sebaliknya semakin tertutup oleh tajuk tanaman maka semakin rendah pencahayaannya. Pantai berpasir memiliki pencahayaannya paling tinggi karena kondisinya sangat terbuka tanpa ada tanaman penutup lahan. Dalam hal ini keberadaan Cemara Laut mampu menurunkan $88 \%$, pencahayaan matahari sehingga suasana di bawah pohon cemara menjadi teduh. Begitu juga pada pengembangan tanaman dengan tingkat kerapatan tajuk yang tinggi dapat meningkatkan kualitas lingkungan (Kusnadi, Jaya, Puspaningsih, Basuki, \& Hakim, 2016). Pencahayaan matahari pada berbagai lokasi pengamatan ditunjukkan pada Gambar 4.

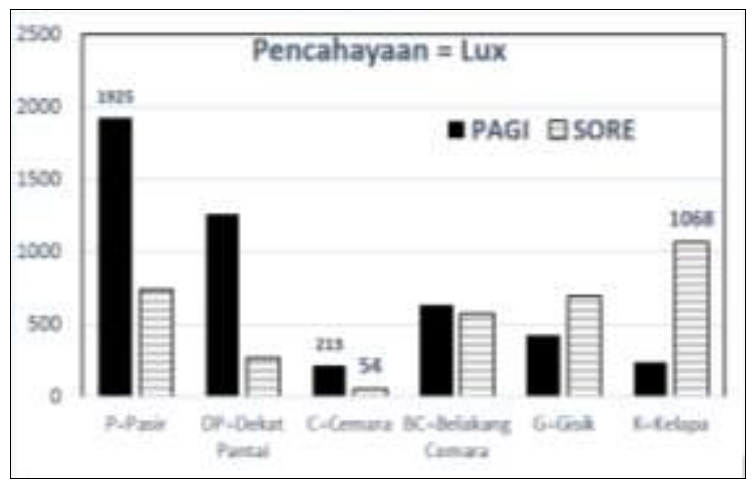

Gambar (Figure) 3. Pencahayaan matahari pada berbagai lahan terbuka dan berkanopi (Solar light penetration in various open field and canopied)

Sumber (Source): Analisis data primer (Primary data analysis)

Beberapa lokasi seperti gisik (gundukan pasir) dan kebun kelapa pada sore hari pencahayaannya lebih tinggi, karena adanya pantulan cahaya disamping juga pada sore hari pencahayaannya semakin meningkat pada daerah terbuka. Cemara Laut terbukti sangat efektif untuk menurunkan cahaya matahari yang masuk ke lahan pantai berpasir, dan kelebihan lain secara teknis perbanyakan Cemara Laut tidak terlalu sulit (Rohaeni, Trikoesoemaningtyas, \& Wirnas, 2014).

\section{B.Perubahan Suhu}

Suhu udara di pantai berpasir Karanggadung, Petanahan berkisar dari $21^{\circ} \mathrm{C}$ sampai $31^{\circ} \mathrm{C}$. Suhu udara pagi hari lebih rendah dibandingkan pada sore hari, dan tertinggi pada siang hari. Perubahan 
suhu udara pada pantai berpasir ditunjukkan pada Gambar 5.

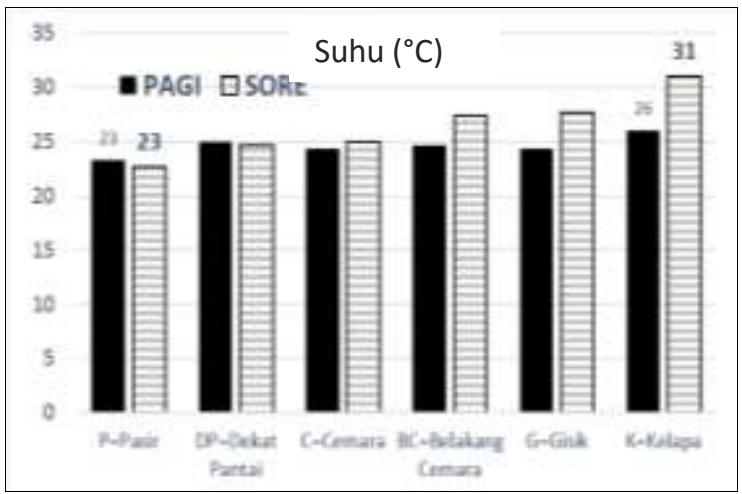

Gambar (Figure) 4. Perubahan suhu udara di Kebumen (Air temperature changes at sandy beach Kebumen)

Sumber (Source): $\quad$ Analisis data primer (Primary data analysis)

Suhu di pantai terbuka paling rendah, hal ini dikarenakan lokasi yang dekat pantai sehingga hembusan udara dengan suhu rendah dari laut dan adanya angin yang mengandung uap air dari lautan (Gambar 6 dan 7). Sebaliknya pada daerah terbuka seperti di kebun kelapa suhu paling tinggi karena jarak tanam yang lebar maka permukaan lahan banyak yang terbuka, dan menyebabkan suhu paling tinggi.

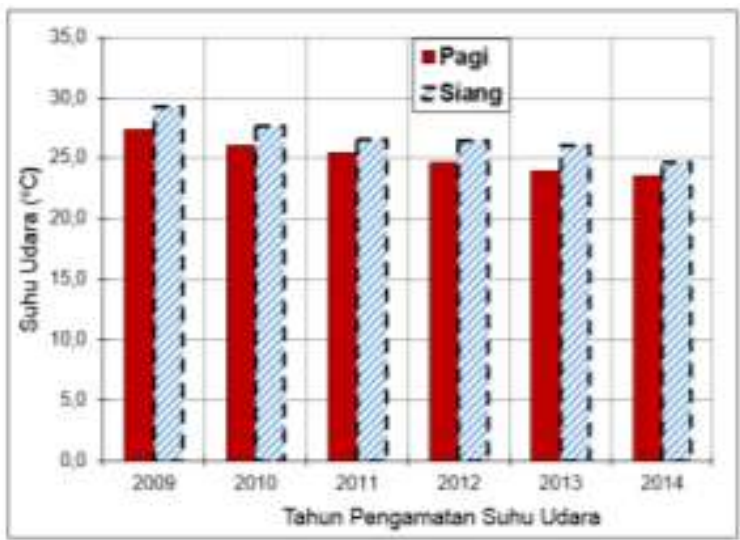

Gambar (Figure) 5. Suhu udara pagi dan siang hari (Air temperature in the morning and in the afternoon at Kebumen)

Sumber(Source): Analisis data primer (Primary data analysis)

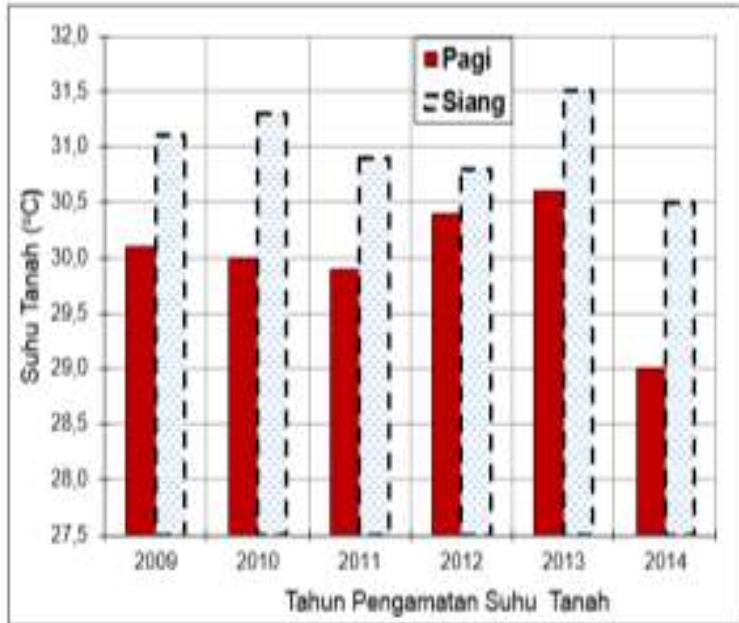

Gambar (Figure) 6. Suhu tanah pagi dan siang hari di Kebumen (Soil temperature in the morning and in the afternoon at Kebumen)

Sumber (Source): Analisis data primer (Primary data analysis)

Suhu pagi hari antara $23-26^{\circ} \mathrm{C}$ dan suhu udara pada sore hari berkisar $23-31^{\circ} \mathrm{C}$. Cemara Laut dapat berfungsi mengendalikan suhu udara tetap stabil atau rendah, sehingga suasana di bawah Cemara Laut terasa tidak panas. Menurut Harjadi \& Octavia (2008) bahwa teknik konservasi tanah Cemara Laut di pantai berpasir akan meningkatkan produktivitas tanaman di belakangnya dan dapat berfungsi sebagai agrowisata.

Suhu tanah pada siang hari lebih tinggi dari pada pagi hari yaitu selisih antara 0,5 ${ }^{\circ} \mathrm{C}$ sampai $2{ }^{\circ} \mathrm{C}$. Suhu tanah tertinggi pada tahun $2013\left(30,5{ }^{\circ} \mathrm{C}-31,5^{\circ} \mathrm{C}\right)$ dan terendah pada tahun $2014\left(29^{\circ} \mathrm{C}-30,5^{\circ} \mathrm{C}\right)$. Kondisi ini menunjukkan bahwa Cemara Laut mampu meningkatkan kondisi iklim semakin baik.

\section{Kelembaban}

Kelembaban udara dari pantai sampai di belakang Cemara Laut $100 \%$ artinya selisih kelembaban udara basah dan kering sama dengan nol atau kelembaban basah sama 
dengan kelembaban kering. Hal ini dapat dilihat pada Gambar 8 dan 9 dibawah ini.

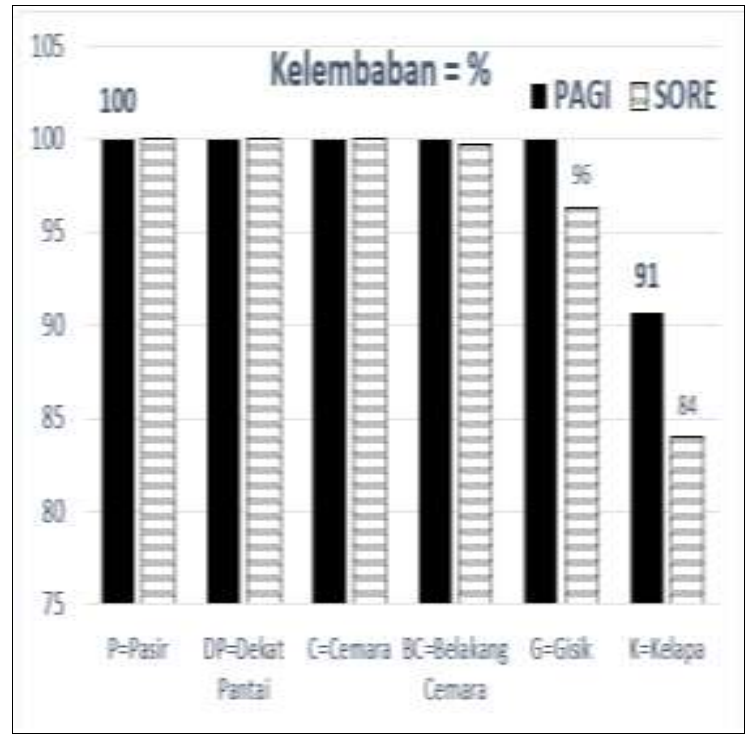

Gambar (Figure) 7. Kondisi kelembaban udara di pantai berpasir Kebumen (The humidity conditions at sandy beach in Kebumen)

Sumber(Source): Analisis data primer (Primary data analysis)

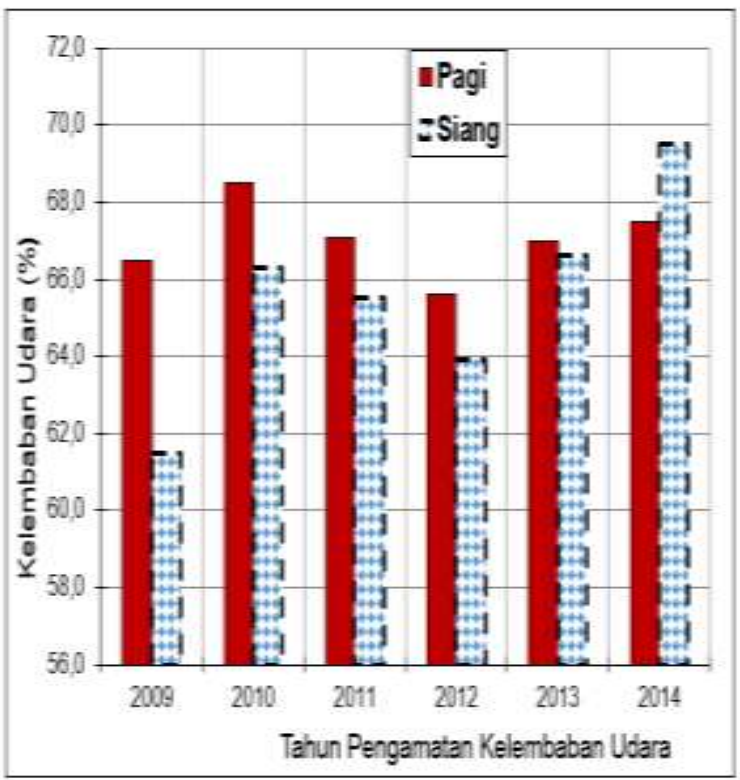

Gambar (Figure) 8. Kelembaban udara pagi dan siang hari di Kebumen (The humidity conditions in the morning and afternoon in Kebumen)

Sumber (Source): $\quad$ Analisis data primer (primary data analysis)

Kelembaban di pantai sangat tinggi hampir semua mendekati $100 \%$ karena adanya uap garam dari air laut, namun uap garam ini sangat berbahaya untuk peralatan yang terbuat dari logam. Kelembaban udara yang tinggi di pantai cukup menguntungkan bagi tanaman di pantai yang gersang (Suriadikusumah \& Pratama, 2010).

Tanaman di belakang Cemara Laut lebih kering yaitu kelembaban mencapai $84 \%$, hal tersebut disebabkan oleh adanya uap garam yang sudah terhalang oleh keberadaan tanaman tanggul angin Cemara Laut, dengan terhalangnya uap garam-garaman akan memberikan ruang tumbuh terhadap tanaman budidaya di sekitarnya.

\section{Tekanan Udara}

Tekanan udara bergerak dari daerah bertekanan tinggi ke daerah bertekanan rendah. Selain tekanan udara, pergerakan udara juga disebabkan oleh pengaruh gerakan gaya corriolis. Akibat dari pergerakan udara berdampak pada: 1) timbulnya pergerakan angin, 2) arah perpindahan udara, 3) terjadi angin siklon dan antisiklon dan 4) pengendalian cuaca.

Udara pada pagi hari mengandung uap air sehingga udara sangat tebal karena ada pergerakan angin lautan menuju daratan disaat para nelayan merapat ke daratan. Semakin siang dan panas terik matahari maka udara semakin menipis dan tekanan udara juga semakin menurun, sehingga semakin kuat angin dari lautan ke daratan, hal tersebut dapat dirasakan pada saat di pantai dari pagi, siang sampai sore hari akan terasa perbedaannya. Gambar 10 menunjukkan tekanan udara tinggi pada 
pagi hari (1011 mb) dan menurun pada sore hari (1007 mb).

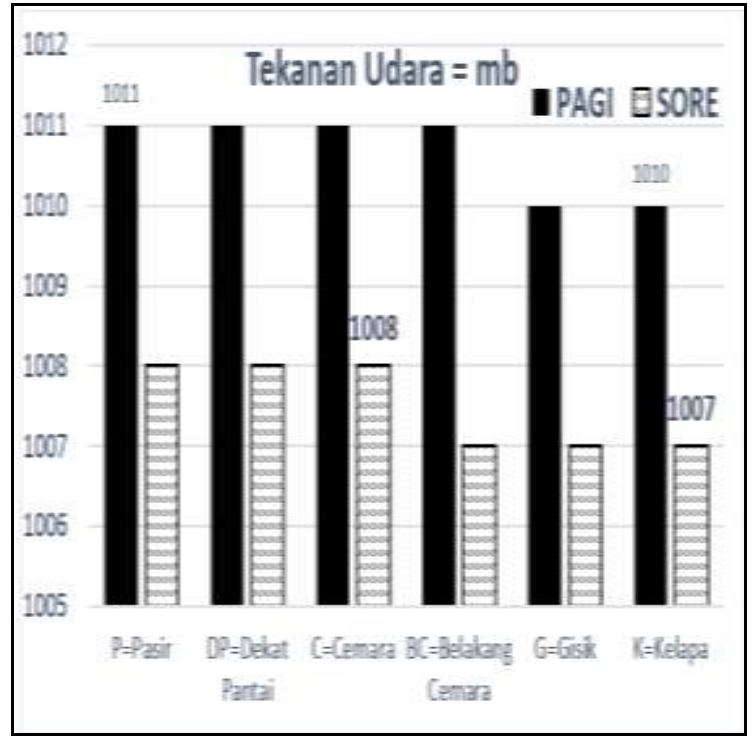

Gambar (Figure) 9. Tekanan udara pada pagi dan sore hari di pantai berpasir Kebumen (Air pressure in the morning and evening at sandy beach in Kebumen)

Sumber (Source): $\quad$ Analisis data primer (Primary data analysis)

\section{E. Ketinggian Tempat}

Ketinggian tempat lahan berpasir berupa gundukan pasir berpengaruh terhadap iklim mikro setempat. Pada lahan berpasir dengan tanaman Cemara Laut yang sudah besar akan menjadi tempat timbunan pasir (gisik). Gisik di pantai selatan Pulau Jawa memiliki karakter khusus yang dipengaruhi ombak dari Samudra Indonesia yang sangat tinggi. Gundukan pasir akan membentuk bukit yang bersifat dinamis, semakin hari semakin meninggi, dan sebaliknya pada bagian lembah akan semakin menurun.

Pada sore hari ketinggian tempat di lahan pantai berpasir semakin tinggi, hal ini karena pada sore hari daratan lebih panas sehingga terjadi angin dari laut ke daratan.
Angin dari laut yang lebih kencang akan membawa partikel lepas berupa pasir menjadi timbunan yang menyebabkan ketinggian gisik meningkat. Letak ketinggian tempat ditunjukkan pada Gambar 11 di bawah ini.

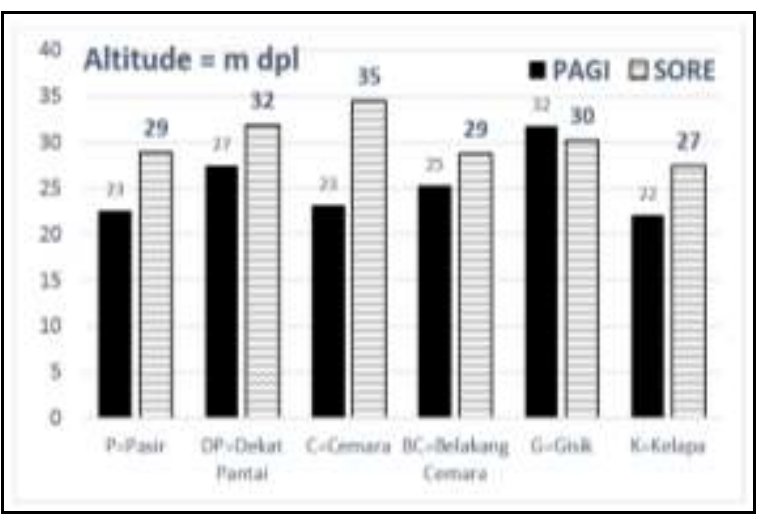

Gambar (Figure) 10. Letak ketinggian tempat pantai berpasir yang fluktuatif (Fluctuation of altitude in the sandy beach).

Sumber (Source): Analisis data primer (Primary data analysis)

Pada lahan pantai berpasir dengan Cemara Laut mampu menangkap gerakan butir-butir pasir maka akan terjadi akumulasi pasir pada lahan Cemara Laut seperti halnya pada bukit gisik yang terus meninggi. Pada sore hari ketinggian tempat semakin meningkat, ini juga disebabkan oleh karena garis pantai yang semakin menurun, sebaliknya pada bulan purnama maka garis pantai akan meningkat. Jika tanah terkikis karena erosi maka akan menyebabkan berkurangnya produktivitas lahan dan berarti akan meningkatkan biaya pengembalian kesuburan tanahnya (van Rijn, 2009).

Menurut Nearing (2013) angin bertiup dari arah datangnya angin badai, meskipun selama musim tertentu beberapa arah yang tidak terduga bisa terjadi. Menurut Slamet et al. (2014) dengan teknologi 
perbaikan tanah pantai berpasir (psamments) akan dapat meningkatkan hasil tanaman sayuran yang ada di belakang Cemara Laut. Pada lahan berpasir yang semakin meninggi gundukan pasirnya karena tertahan Cemara Laut, maka suhu semakin membaik dan kesuburan tanah juga meningkat. Pengelolaan lahan pantai agar tidak rusak dan tergerus abrasi dan erosi angin dapat dilakukan tindakan penghijauan dengan Cemara Laut untuk lahan pantai berpasir dan untuk pantai yang berlumpur dapat dilakukan dengan penanaman tanaman Mangrove (Loarie, Duffy, \& Hamilton, 2009).

\section{KESIMPULAN}

Peranan Cemara Laut (C. equisetifolia) dalam upaya perbaikan iklim mikro yang dilakukan dengan tindakan reboisasi atau penghijauan sangat positif, hal tersebut dapat dilihat dengan semakin membaiknya kondisi pencahayaan sinar matahari, suhu udara, kelembaban, tekanan udara dan ketinggian tempat sejak tahun 2009 sampai 2014.

Beberapa kondisi positif dengan adanya Cemara Laut di pantai selatan Karanggadung, Kebumen tersebut antara lain meliputi: 1) intensitas cahaya mengalami penurunan 1925 lux menjadi 213 lux, 2) suhu udara turun dari $31{ }^{\circ} \mathrm{C}$ menjadi $25{ }^{\circ} \mathrm{C}$, 3) kelembaban meningkat dari $84 \%$ menjadi $100 \%$, 4) tekanan udara meningkat dari 1007 mb menjadi 1008 mb dan 5) ketinggian gisik mengalami peningkatan $27 \mathrm{~m}$ dpl menjadi $35 \mathrm{~m}$ dpl. Lebih lanjut perlu dikembangkan penelitian di masa mendatang pada lahan berlumpur dengan melihat pengaruh tanaman mangrove dalam upaya mencegah terjadinya abrasi pantai.

\section{UCAPAN TERIMA KASIH}

Ucapan terima kasih diucapkan kepada para Peneliti dan Teknisi Balai Penelitian dan Pengembangan Teknologi Pengelolaan Daerah Aliran Sungai (BPPTPDAS) di Surakarta. Warga dan Aparat Desa Karanggadung, Kecamatan Petanahan, Kabupaten Kebumen, Staf Dinas Kehutanan, Dinas Pariwisata, dan Instansi Dinas lainnya. Serta Para Staf Pemda dan Bupati Kebumen.

\section{DAFTAR PUSTAKA}

Budiyanto, G. (2011). Teknologi konservasi lanskap gumuk pasir Pantai Parangtritis Bantul DIY, Jurnal Lanskap Indonesia 3(2), 97-101.

Daryono, B. S., Purnomo, P., Sidiq, Y., \& Maryanto, S. D. (2016). Pengembangan sentra budidaya melon di Pantai Bocor Kabupaten Kebumen melalui implementasi education for sustainable development. Bioeksperimen: Jurnal Penelitian Biologi, 2(1), 44-53.

Hani, A., \& Rachman, E. (2016). Pertumbuhan Tanaman Nyamplung sampai umur 4 (empat) tahun pada tiga pola tanam dan dosis pupuk di lahan Pantai Berpasir Pangandaran, Jawa Barat. Jurnal Penelitian Kehutanan Wallacea 5(2), 151-158.

Harjadi, B., \& Octavia, D. (2008). Penerapan teknik konservasi tanah di pantai berpasir untuk agrowisata. Info Hutan 5(2), 113-121.

Kusnadi, Jaya, I. N. S., Puspaningsih, N., Basuk, M., \& Hakim, L. (2016). Model 
penduga kualitas tempat tumbuh Jati (Tectona grandis) menggunakan citra resolusi sangat tinggi pesawat tidak berawak di KPH Nganjuk, Jurnal Penelitian Kehutanan Wallacea 5(2), 185-194.

Loarie, S. R., Duffy, P. B., \& Hamilton, H. (2009). The velocity of climate change. Nature, 462, 1052-1055. https://doi.org/10.1038/nature0864 9

Nearing, M. A. (2013). Soil erosion and conservation. In Environmental modelling: Finding simplicity in complexity: Second Edition (pp. 365378).

https://doi.org/10.1002/9781118351 475.ch22

Rohaeni, W. R., Trikoesoemaningtyas, \& Wirnas, D. (2014). Keragaan fenotipik kedelai pada dua kondisi intensitas cahaya ekstrim. AGROTROP, 4(1), 8387.

Slamet, A. S., Siregar, H. H., \& Kustiyo, A. (2014). Vehicle routing problem (VRP) dengan algoritma genetika pada pendistribusian sayuran dataran tinggi. Jurnal Teknologi Industri Pertanian, 24(1), 1-10.

Suriadikusumah, A., \& Pratama, dan A. (2010). Penetapan kelembaban, tekstur tanah dan kesesuaian lahan untuk Tanaman Kina (Chinchona spp) di Sub DAS Cikapundung Hulu melalui Citra Satelit Landsat TM Image. Jurnal Agrikultura, 21(1), 85-92.

van Rijn, L. C. (2009). Prediction of dune erosion due to storms. Coastal Engineering, 56(4), 441-457. https://doi.org/10.1016/j.coastaleng. 2008.10.006 